OPEN ACCESS

Edited by:

Markus Wirth,

Klinikum rechts der Isar, Germany

Reviewed by:

Daniel Jira,

Technical University of Munich,

Germany

Alfredo Mauricio Batista De Paula,

Unimontes, Brazil

Maria Buchberger,

Technical University of Munich,

Germany

${ }^{*}$ Correspondence:

Bing Yan

yanbing_west@163.com

San-Gang Wu

wusg@xmu.edu.cn

${ }^{\text {t}}$ These authors have contributed equally to this work

Specialty section: This article was submitted to Head and Neck Cancer, a section of the journal

Frontiers in Oncology

Received: 21 June 2021 Accepted: 01 November 2021

Published: 26 November 2021

Citation:

Zhou P, Chen J-X, Zhou Y, Lian C-L, Yan B and Wu S-G (2021)

Rare Metastasis to the

Submandibular Gland in Oral

Squamous Cell Carcinoma.

Front. Oncol. 11:728230.

doi: 10.3389/fonc.2021.728230

\section{Rare Metastasis to the Submandibular Gland in Oral Squamous Cell Carcinoma}

\author{
Ping Zhou ${ }^{1+}$, Jing-Xin Chen ${ }^{2 \dagger}$, Yuan Zhou ${ }^{1+}$, Chen-Lu Lian ${ }^{1}$, Bing Yan ${ }^{3 *}$ \\ and San-Gang $\mathrm{Wu}^{1 *}$ \\ ${ }^{1}$ Department of Radiation Oncology, The First Affiliated Hospital of Xiamen University, Xiamen, China, ${ }^{2}$ Department of \\ Stomatology, Hainan General Hospital (Hainan Affiliated Hospital of Hainan Medical University), Haikou, China, ${ }^{3}$ Department \\ of Otolaryngology Head and Neck Surgery, The First Affiliated Hospital of Xiamen University, Xiamen, China
}

Purpose: In the current recommendation of neck dissection in oral squamous cell carcinoma (OSCC), the submandibular gland (SMG) should also be removed. This study aimed to investigate the incidence and the patterns of SMG involvement in OSCC patients.

Methods: Patients initially diagnosed with OSCC between January 2018 and October 2020 were included. The distribution of lymph nodes metastasis in level IB was analyzed.

Results: We included 145 patients who underwent primary surgery and neck dissection in this study. All patients had level IB lymph node dissection and simultaneous removal of the SMG. Of these patients, only one patient $(0.7 \%)$ had involvement in SMG by directly infiltrating from the primary tumor. A total of 18 positive lymph nodes were found in level IB in 16 patients, and no positive lymph nodes were located in the SMG. There were 6 lymph nodes located in the lateral part of the SMG and 12 lymph nodes located in the anterior of the SMG. Patients with tumors located in the buccal mucosa and N3 stage were the independent predictive factors associated with level IB nodal metastasis.

Conclusion: Involvement of SMG in OSCC is quite rare. Preservation of the SMG during neck dissection in selected patients with OSCC seems to be feasible and oncologically safe.

Keywords: oral squamous cell carcinoma, submandibular gland, organ preservation, level IB metastasis, head and neck cancer

\section{INTRODUCTION}

According to the GLOBOCAN 2020, cancers developed in the lip and oral cavity accounted for approximately $2 \%$ of all cancers in the world, with over 370,000 cases newly diagnosed with lip and oral cavity cancers and 170,000 disease-related deaths occurring annually (1). The majority of oral cavity cancers are squamous cell carcinoma (SCC) (2). Approximately $29 \%-36 \%$ of oral squamous cell carcinoma (OSCC) patients had cervical lymph node involvement $(3,4)$. In patients with earlystage (T1) and clinically lymph node-negative disease, $23 \%$ of them had occult lymph node 
metastasis during neck dissection (5). Therefore, primary surgery and neck dissection remain the most important management for OSCC (6).

The submandibular gland (SMG), which is located in the submandibular triangle, has the predominant function of saliva secretion. According to the 2013 edition of the neck nodal classification in the neck, SMG is one of the contents of level IB (7). A large case series from a literature review included 2,750 patients with OSCC, and only 2 patients $(0.07 \%)$ had intraglandular lymph node metastases (8). In addition, the probability of direct involvement to SMG by primary tumor or periglandular nodal extension through the capsule was only $0 \%-$ $4.5 \%$ (8). Moreover, the prior study also showed comparable survival outcomes between the SMG preservation group and the removal group (9). However, in the current clinical practice, SMG excision is a regular part of level IB dissection in OSCC. In this study, we aimed to investigate the incidence and risk factors of SMG involvement in OSCC patients, which could add to the knowledge regarding the preservation of $S M G$ in this patient subset.

\section{MATERIALS AND METHODS}

\section{Data Collection and Patient's Selection Criteria}

We retrospectively included patients diagnosed with OSCC between January 2018 and October 2020. Patients who met the following criteria were included in this study: (1) histopathologically confirmed SCC, (2) primary tumor located in the oral cavity, (3) received primary tumor resection and ipsilateral with or without contralateral neck dissection, and (4) removal of ipsilateral level IB and simultaneous removal of the SMG. All cases of OSCC were confirmed by histopathology. Patients who received preoperative chemotherapy, preoperative radiotherapy, or preoperative chemoradiotherapy were excluded. The study was approved by the Institutional Review Board of the First Affiliated Hospital of Xiamen University (approval number: XMYY-2021KY052). Written informed consent for participation was not required for this study in accordance with the national legislation and the institutional requirements.

\section{Measures}

OSCC in our institution was generally treated with primary surgical resection with concomitant neck dissection. All patients received standard neck dissection due to the higher incidence of occult nodal metastasis in OSCC $(10,11)$. The extent of neck dissection included a minimum of levels I-III with SMG resection in all cases. Bilateral neck dissection was conducted in those with tumors involving or approaching the midline. The following clinicopathologic characteristics were identified, including gender, age, primary tumor sites, smoking use, alcohol use, tumor grade, tumor $(\mathrm{T})$ stage, nodal $(\mathrm{N})$ stage, American Joint Committee on Cancer (AJCC) stage, surgery margin status, and the details of neck dissection. Slides stained with hematoxylin and eosin were assessed to confirm the diagnosis and to perform histopathological grading of the tumors based on the adaptation from Bryne et al. (12). The distribution of lymph node involvement in level IB and around the SMG was analyzed. The eighth edition of the AJCC staging was used in this study, which integrated the depth of invasion and extranodal extension into the tumor-node-metastasis (TNM) classification systems, respectively (13).

\section{Statistical Analysis}

The logistic regression analysis was performed to identify predictive factors associated with level IB lymph node metastasis. SPSS statistical software (version 25.0, IBM Corporation, Armonk, NY, USA) was used for data analysis. $p<0.05$ was considered to be statistically significant.

\section{RESULTS}

\section{Patients' Clinicopathological Characteristics}

A total of 145 patients were identified in this study, namely, 96 males (66.2\%) and 49 females (33.8\%). The median age was 60 years (range, 27-83 years). Table 1 lists the baseline characteristics of patients. Of these patients, 106 (73.1\%), 20 (13.8\%), 9 (6.2\%), and $7(4.8 \%)$ had tumors developed in the tongue, buccal mucosa, the floor of the mouth, and gingiva, respectively. In patients with available tumor grade $(n=143)$, moderately differentiated disease predominated with $76.2 \%(n=$ $109)$, and $11.9 \%(n=17)$ and $11.9 \%(n=17)$ of them were poorly differentiated and well-differentiated, respectively. There were 49 (33.8\%), 64 (44.1\%), 54 (14.5\%), and 11 (7.6\%) patients who had stage T1, T2, T3, and T4 diseases, respectively. A total of 117 (80.7\%) patients underwent ipsilateral neck dissection and 28 (19.3\%) underwent bilateral neck dissection. Sixty-one patients $(42.1 \%)$ were pathologically diagnosed with lymph node metastases, including 11 (18.0\%), 36 (59.0\%), and 14 (23.0\%) patients who had stage $\mathrm{N} 1, \mathrm{~N} 2$, and $\mathrm{N} 3$ diseases, respectively. According to the 8th TNM staging, there were 38 (26.2\%), 34 $(23.4 \%), 20(13.8 \%)$, and $53(36.6 \%)$ patients who were pathologically diagnosed with stage I, II, III, and IVA diseases, respectively. Most of the patients (95.9\%) had negative surgical margins.

Among all patients, 76 (52.4\%) had a history of alcohol use, including $31(40.8 \%, 31 / 76)$ patients with a history of alcohol abuse. In patients with alcohol abuse, the median daily Chinese Baijiu consumption was $150 \mathrm{ml}$ (range, 50-700 ml), and the median alcohol intake time was 30 years (range, 2-40 years). In addition, there were $64(44.1 \%)$ patients who had a history of smoking, the median smoking intensity was 20 (range, 2-60) cigarettes per day, the median smoking time was 30 years (range, 5-50 years), and the median smoking index was 30 pack-years (range, 2-120 pack-years).

\section{SMG Invasion}

Only one patient $(0.7 \%)$ with stage IVA disease and primary tumor located in the tongue had involvement of the SMG. 
TABLE 1 | Patient characteristics.

\begin{tabular}{|c|c|}
\hline Variables & Number (\%) \\
\hline \multicolumn{2}{|l|}{ Gender } \\
\hline Male & $96(66.2)$ \\
\hline Female & 49 (33.8) \\
\hline \multicolumn{2}{|l|}{ Age } \\
\hline$<50$ years & $33(22.8)$ \\
\hline$\geq 50$ years & $112(77.2)$ \\
\hline \multicolumn{2}{|l|}{ Primary site } \\
\hline Lip & $1(0.7)$ \\
\hline Upper jaw & $1(0.7)$ \\
\hline Buccal mucosa & $20(13.8)$ \\
\hline Mouth floor & 9 (6.2) \\
\hline Retromolar trigone & $1(0.7)$ \\
\hline Tongue & $106(73.1)$ \\
\hline Gingiva & $7(4.8)$ \\
\hline \multicolumn{2}{|l|}{ Smoking pack-year index } \\
\hline 0 & $81(55.9)$ \\
\hline$<20$ & $17(11.7)$ \\
\hline$\geq 20$ & $47(32.4)$ \\
\hline \multicolumn{2}{|l|}{ Alcohol use } \\
\hline Never & $69(47.6)$ \\
\hline Normal & $45(31.0)$ \\
\hline Abuse & $31(21.4)$ \\
\hline \multicolumn{2}{|l|}{ Tumor grade } \\
\hline Well differentiation & $17(11.7)$ \\
\hline Moderate differentiation & $109(75.2)$ \\
\hline Poor differentiation & $17(11.7)$ \\
\hline Unknown & $2(1.4)$ \\
\hline \multicolumn{2}{|l|}{ Tumor stage } \\
\hline $\mathrm{T} 1$ & 49 (33.8) \\
\hline T2 & $64(44.1)$ \\
\hline T3 & $21(14.5)$ \\
\hline T4 & $11(7.6)$ \\
\hline \multicolumn{2}{|l|}{ Nodal stage } \\
\hline NO & $84(57.9)$ \\
\hline N1 & $11(7.6)$ \\
\hline N2 & $36(24.8)$ \\
\hline N3 & $14(9.7)$ \\
\hline \multicolumn{2}{|l|}{ AJCC stage } \\
\hline 1 & $38(26.2)$ \\
\hline$\|$ & $34(23.4)$ \\
\hline III & $20(13.8)$ \\
\hline IVA & $53(36.6)$ \\
\hline \multicolumn{2}{|l|}{ Margin status } \\
\hline Negative & $139(95.9)$ \\
\hline Positive & $6(4.1)$ \\
\hline \multicolumn{2}{|l|}{ Neck dissection } \\
\hline Ipsilateral & $117(80.7)$ \\
\hline Bilateral & $28(19.3)$ \\
\hline \multicolumn{2}{|c|}{ Submandibular gland involved } \\
\hline No & $144(99.3)$ \\
\hline Yes & $1(0.7)$ \\
\hline
\end{tabular}

AJCC, American Joint Committee on Cancer; T, tumor; N, nodal.

The SMG was involved by direct infiltration from the ventral tongue (Figure 1). This patient was a 57-year-old man who was clinically diagnosed with $\mathrm{T} 4 \mathrm{~N} 2 \mathrm{bM} 0$ oral tongue cancer. The maximum diameter of the primary tumor was $6.8 \mathrm{~cm}$. Ipsilateral neck dissection was performed. There were 36 lymph nodes that were dissected and 2 were metastasized. A preoperative computed tomography scan showed that the SMG was directly infiltrated by the primary tumor.

\section{Peri-Submandibular Node Involvement}

In the 61 patients with pathologically nodal positive diseases, level II was the most common site of regional lymph node metastasis $(n=57)$, followed by level III $(n=21)$, level IB $(n=$ $16)$, level IA $(n=2)$, and level IV $(n=1)$. A total of 18 positive lymph nodes were found in level IB in 16 patients. The median maximum diameter of the positive lymph nodes around level IB was $1.49 \mathrm{~cm}$ (range, 1.17-2.61 cm). The patterns of perisubmandibular lymph node metastases are displayed in Figures 2-4. There were 6 lymph nodes in the lateral part of the SMG, and 12 were shown in the anterior of the SMG. However, no positive lymph node was observed in the medial or internal side of the SMG.

\section{Risk Factors Associated With Level IB Lymph Node Metastasis}

The logistic regression test was performed to determine the predictive factors associated with level IB lymph node metastasis (Table 2). The results showed that patients with tumors located in the buccal mucosa (the odds ratio [OR] for buccal mucosal cancer compared to tongue cancer was 6.852 , $95 \%$ confidence interval [CI] $1.375-34.144, p=0.019)$ and N3 stage (the OR for stage N3 disease compared to stage N1 disease was 13.333, 95\%CI 1.321-134.615, $p=0.028$ ) were the independent predictive factors associated with level IB lymph node metastasis.

\section{DISCUSSION}

In our study, we aimed to investigate the rationality of SMGsparing neck dissection among patients with OSCC. Our study showed that only one patient $(0.7 \%)$ had SMG involvement, and direct involvement was the most common way of SMG involvement in OSCC patients.

Although the neck dissection procedure has undergone several improvements, the SMG dissection was always recommended in $\operatorname{OSCC}(14,15)$. In recent years, a growing number of evidence showed that the preservation of noninvaded SMG may be feasible in $\operatorname{OSCC}(8,9,16)$. There are three potential patterns of SMG involvement: anatomic proximity, hematogenous metastasis, and lymphatic spread (17). SMG is thought to lack a blood vessel network, which is different from other glands (17). Although a prior literature review showed a low risk of SMG metastasis in breast, lung, and renal cancers (18), no hematogenous metastasis in SMG was found in OSCC patients $(17,19,20)$. In addition, SMG was thought to lack a lymphatic vessel network (17). Zeng et al. made a literature review that included 2,750 patients, and they found that only $0.07 \%$ of patients had intraglandular lymph node metastases (8). Furthermore, direct involvement was the main pattern of SMG involvement in OSCC (1\%-2.9\%) $(16,17,19$, $21)$. In our study, there was only one $(0.7 \%)$ OSCC patient who had SMG involvement by direct infiltration from the primary tumor, which was similar to the above studies. Therefore, direct 


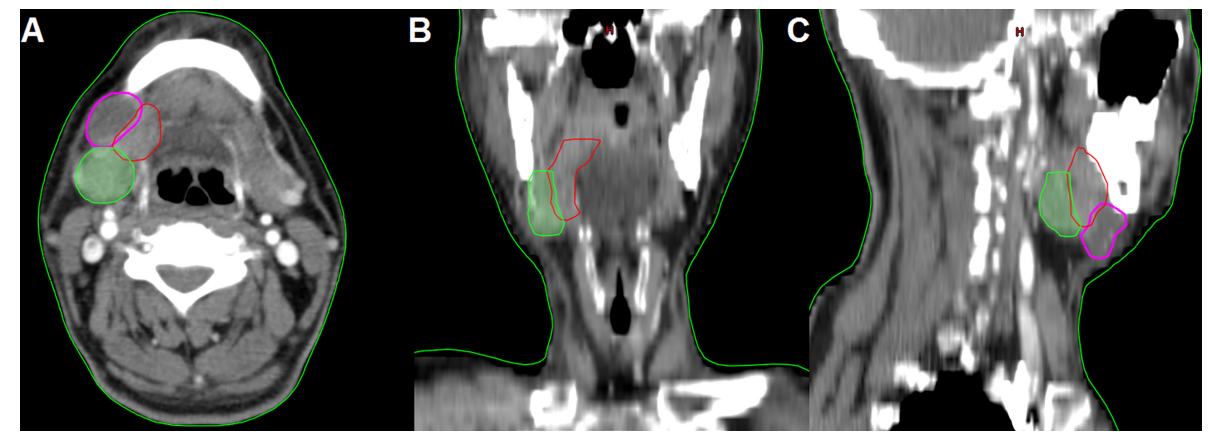

FIGURE 1 | The preoperative computed tomography image of submandibular gland involvement in axial (A), coronal (B), and sagittal views (C) (red, primary tumor; purple, lymphadenopathy in level IB; green, submandibular gland).

involvement is the most common pattern of SMG involvement in OSCC patients.

SMG is located in level IB according to the current recommendation of neck nodes delineation guideline (7). Fives et al. reported that approximately $44.4 \%$ of OSCC patients had pathologically confirmed positive lymph nodes in level I (4). In our study, 61 patients had pathologically nodal positive diseases and $26.2 \%$ of them $(n=18)$ had positive lymph nodes in level IB. Although the rate of level IB lymph node metastasis was relatively high in OSCC, the literature review showed that only

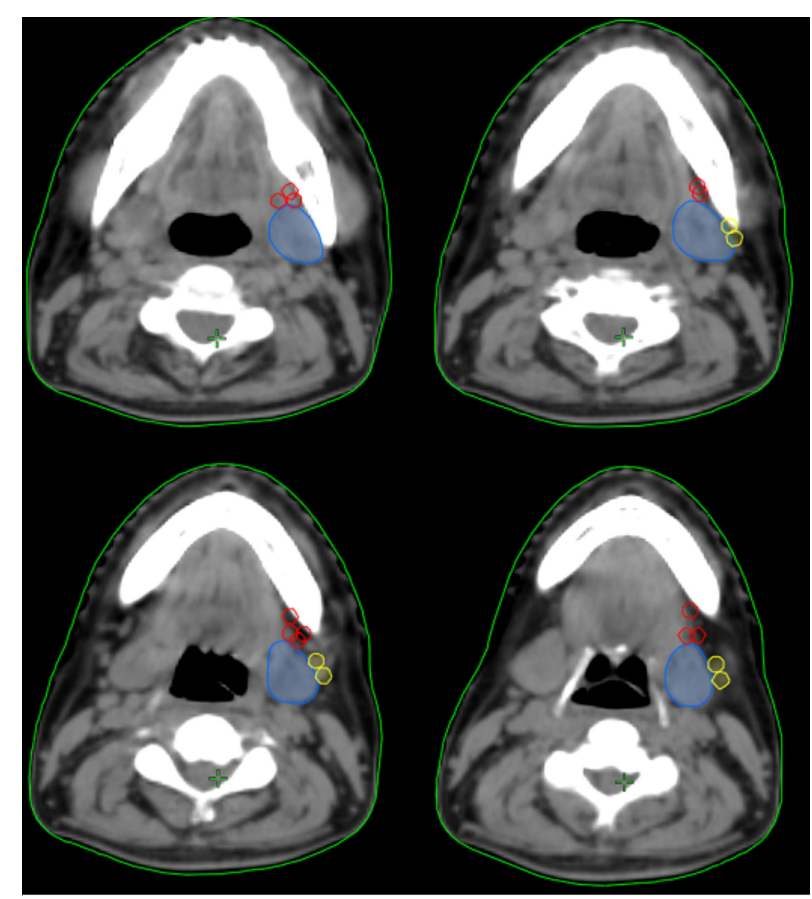

FIGURE 2 | The patterns of peri-submandibular lymph node metastases in oral squamous cell carcinoma (blue, submandibular gland; red, lymph node metastases in the anterior part of the submandibular gland; yellow, lymph node metastases in the lateral part of the submandibular gland).
$2.05 \%$ of patients had SMG involvement (8). In our study, no SMG involvement was observed through periglandular nodal extension. Peri-SMG lymph nodes are divided into six subgroups, and the deep groups have fewer lymph nodes, which have little clinical significance (22). In our study, there were 6 lymph nodes in the lateral part of SMG, 12 in the anterior of SMG, and no lymph node was observed in the medial or internal side of SMG. A large cohort of patients with nasopharyngeal carcinoma also showed no patients had SMG metastasis or metastasis to the medial edge of SMG (23). In the

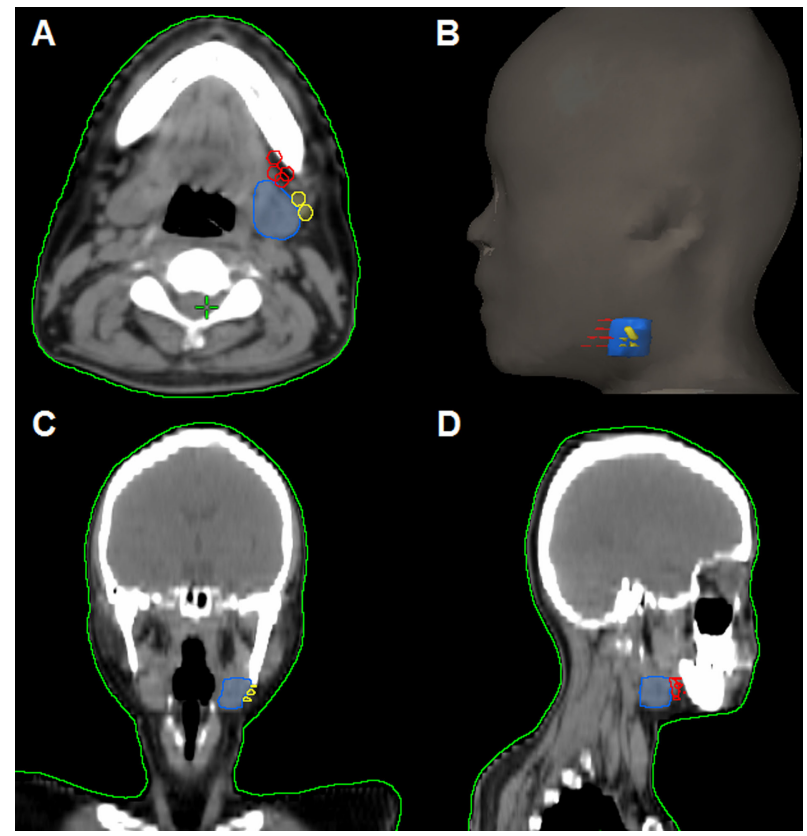

FIGURE 3 | The patterns of peri-submandibular lymph node metastases in axial (A), three-dimensional (B), coronal (C), and sagittal views (D) (blue, submandibular gland; red, lymph node metastases in the anterior part of the submandibular gland; yellow, lymph node metastases in the lateral part of the submandibular gland). 


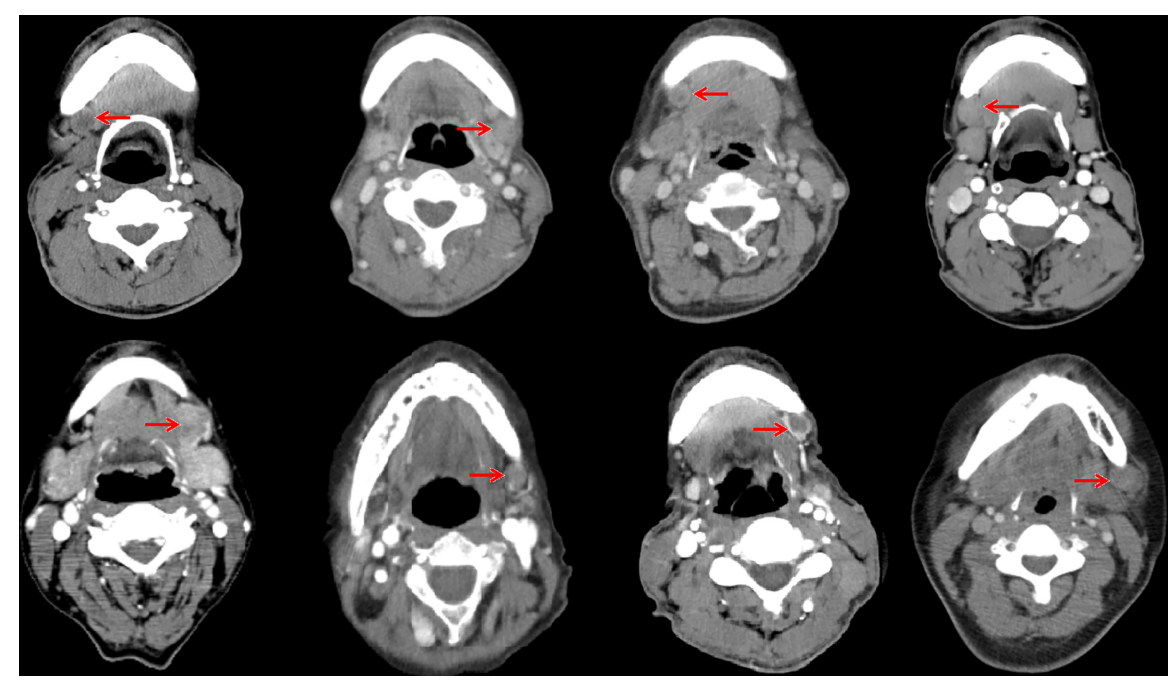

FIGURE 4 | Computed tomography axial images from patients with lymphadenopathy in level IB (red arrow, lymphadenopathy in level IB).

TABLE 2 | Independent predictive factors associated with level IB lymph node metastasis in patients with node-positive disease $(n=61)$.

\begin{tabular}{|c|c|c|c|}
\hline Variables & OR & $95 \% \mathrm{Cl}$ & $p$ \\
\hline \multicolumn{4}{|l|}{ Gender } \\
\hline Male & 1 & & \\
\hline Female & 0.418 & $0.104-1.689$ & 0.221 \\
\hline \multicolumn{4}{|l|}{ Age } \\
\hline$<50$ years & 1 & & \\
\hline$\geq 50$ years & 0.553 & $0.138-2.217$ & 0.403 \\
\hline \multicolumn{4}{|l|}{ Primary sites } \\
\hline Tongue & 1 & & \\
\hline Buccal mucosa & 6.852 & $1.375-34.144$ & 0.019 \\
\hline Others & 1.644 & $0.273-9.892$ & 0.587 \\
\hline \multicolumn{4}{|l|}{ Alcohol use } \\
\hline No & 1 & & \\
\hline Normal & 1.971 & $0.527-7.374$ & 0.313 \\
\hline Abuse & 0.821 & $0.179-3.374$ & 0.800 \\
\hline \multicolumn{4}{|l|}{ Smoking pack-year index } \\
\hline 0 & 1 & & \\
\hline$<20$ & 1.667 & $0.329-8.434$ & 0.537 \\
\hline$\geq 20$ & 0.741 & $0.194-2.830$ & 0.661 \\
\hline \multicolumn{4}{|l|}{ Tumor differentiation } \\
\hline Well differentiation & 1 & & \\
\hline Moderate differentiation & 0.455 & $0.066-3.113$ & 0.422 \\
\hline Poor differentiation & 0.667 & $0.078-5.678$ & 0.711 \\
\hline \multicolumn{4}{|l|}{ Tumor stage } \\
\hline $\mathrm{T} 1$ & 1 & & \\
\hline $\mathrm{T} 2$ & 0.913 & $0.193-4.330$ & 0.909 \\
\hline T3 & 0.667 & $0.089-4.994$ & 0.693 \\
\hline $\mathrm{T} 4$ & 3.000 & $0.447-20.153$ & 0.258 \\
\hline \multicolumn{4}{|l|}{ Nodal stage } \\
\hline N1 & 1 & & \\
\hline N2 & 2.414 & $0.263-22.117$ & 0.436 \\
\hline N3 & 13.333 & $1.321-134.615$ & 0.028 \\
\hline \multicolumn{4}{|l|}{ Margin status } \\
\hline Negative & 1 & & \\
\hline Positive & 0.933 & $0.090-9.677$ & 0.954 \\
\hline
\end{tabular}

OR, odds ratio; Cl, confidence interval; $T$, tumor; $N$, nodal. current clinical practice, resection of all lymph nodes in level IB and preservation of the SMG are technically feasible for OSCC patients (24). Therefore, with careful preoperative imaging evaluation and intraoperative evaluation of the relationship between primary tumor and metastatic lymph nodes or SMG, SMG-sparing neck dissection may be feasible and safe if the SMG is not involved.

The SMG secretes approximately $70 \%-90 \%$ of the amount of unstimulated salivary, especially at night (25). Saliva plays an important role in oral cavity lubrication, oral antimicrobial activity maintenance, tooth remineralization, and oral mucosal immunity (17). Removal of SMG would increase the incidence of xerostomia and influence the quality of life (17). In addition, in OSCC patients receiving adjuvant radiotherapy, the irradiation of the contralateral SMG could further increase xerostomia because SMG is a part of level IB treatment in the consensus guidelines (7). Moreover, resection of the SMG may also result in external contour defects in the neck (26). Several studies have found that the SMG may be involved by direct invasion of the primary lesion or by spread from adjacent metastatic cervical lymph nodes $(21,27)$. Advanced T stage and mouth floor tumors were also the risk factors for a direct invasion of SMG $(17,22,26$, 28). In our study, we did not analyze the relationship between clinicopathological factors associated with SMG involvement because limited patients had SMG involvement. We only found one patient with T4N2bM0 oral tongue cancer who had a tumor infiltrated to SMG.

In the recent two decades, there has been controversy over whether SMG needs to be removed in OSCC. With the in-depth understanding of the patterns of lymph node metastases in the neck, selective neck dissection has become widely accepted in the treatment of OSCC. The distribution of lymph node metastases in the neck in our study was similar to the previous studies (29, 
30). Since the SMG does not contain intraglandular lymph nodes, removal of an uninvolved SMG may not always be necessary, which has the potential benefit to reduce postoperative xerostomia (26). We also only found one patient with SMG involvement by direct invasion of the primary tumor. The study from Chen et al. showed that stage T4 disease and N2b-N3 tumors were the risk factor for SMG invasion, especially for those with buccal mucosal cancer and cancer located in the alveolar ridge (28). Therefore, the anatomical proximity of primary cancer must be taken into consideration while evaluating the patient for SMG preservation.

According to previous studies, the true infiltration of the SMG by OSCC is quite rare, suggesting that the SMG might not be contaminated and thus be considered to be preserved during level IB lymph node dissection $(17,26,28)$. However, we should emphasize the limited insight into the operating field when preserving the SMG during neck dissection, including the risk of nerve injuries and the risk of missing affected lymph nodes $(9,31)$. In the clinical practice, the protection of SMG may also be safe. Zeng et al. confirmed the oncological safety of SMG flaps in repairing postoperative OSCC defects (8). Moreover, SMG transplantation to the anterior submental region has been found to protect the gland from the dry mouth during radiotherapy (32). Regarding the contemporary radiotherapy techniques, William et al. demonstrated the feasibility of SMG preservation by maintaining a mean dose to the gland of $\leq 39$ Gy (33).

In our study, patients with buccal mucosal cancer and N3 stage have a higher risk of level IB metastasis. However, there was no significant association between $\mathrm{T}$ stage and level IB metastasis. Several studies also have shown that the $\mathrm{T}$ stage was not a risk factor for level IB metastasis $(16,26,34)$.

Several limitations should be acknowledged in the current study. First, it was a retrospective study with relatively small sample size. Second, our study does not include information on actual complaints by patients concerning the removal of SMG. Third, as the follow-up time in our study was relatively short, a long-term observation is required to determine the risk of tumor recurrence in level IB. Finally, the long-term safety of SMG preservation in OSCC should be performed by the prospective studies. Despite these limitations, we believe that our findings add the knowledge regarding the preservation of SMG for OSCC patients.

\section{REFERENCES}

1. Sung H, Ferlay J, Siegel RL, Laversanne M, Soerjomataram I, Jemal A, et al. Global Cancer Statistics 2020: GLOBOCAN Estimates of Incidence and Mortality Worldwide for 36 Cancers in 185 Countries. CA Cancer J Clin (2021) 71(3):209-49. doi: 10.3322/caac.21660

2. Pulte D, Brenner H. Changes in Survival in Head and Neck Cancers in the Late 20th and Early 21st Century: A Period Analysis. Oncologist (2010) 15 (9):994-1001. doi: 10.1634/theoncologist.2009-0289

3. Zanoni DK, Montero PH, Migliacci JC, Shah JP, Wong RJ, Ganly I, et al. Survival Outcomes After Treatment of Cancer of the Oral Cavity (1985-2015). Oral Oncol (2019) 90:115-21. doi: 10.1016/j.oraloncology.2019.02.001

4. Fives C, Feeley L, Sadadcharam M, O'Leary G, Sheahan P. Incidence of Intraglandular Lymph Nodes Within Submandibular Gland, and

\section{CONCLUSION}

In conclusion, our study suggests that the involvement of SMG is extremely rare in OSCC. Preservation of the SMG during neck dissection in selected patients with OSCC seems to be feasible and oncologically safe. More studies are needed to investigate the candidates who may be feasible and safe to preserve SMG.

\section{DATA AVAILABILITY STATEMENT}

The raw data supporting the conclusions of this article is available from the corresponding author on reasonable request.

\section{ETHICS STATEMENT}

The study was approved by the Institutional Review Board of the First Affiliated Hospital of Xiamen University. Written informed consent for participation was not required for this study in accordance with the national legislation and the institutional requirements.

\section{AUTHOR CONTRIBUTIONS}

PZ, J-XC, YZ, BY, and S-GW are lead authors who participated in data collection, manuscript drafting, tables/figures creation, and manuscript revision. PZ and C-LL aided in data collection. $\mathrm{PZ}, \mathrm{J}-\mathrm{XC}$, and $\mathrm{YZ}$ are senior authors who aided in drafting the manuscript and manuscript revision. BY and S-GW are the corresponding authors who initially developed the concept and drafted and revised the manuscript. All authors contributed to the article and approved the submitted version.

\section{FUNDING}

This work was partly supported by the Key R\&D Plan of Hainan Province (No. ZDYF2021SHFZ115).

Involvement by Floor of Mouth Cancer. Eur Arch Otorhinolaryngol (2017) 274(1):461-6. doi: 10.1007/s00405-016-4205-0

5. Peng KA, Chu AC, Lai C, Grogan T, Elashoff D, Abemayor E, et al. Is There a Role for Neck Dissection in T1 Oral Tongue Squamous Cell Carcinoma? The UCLA Experience. Am J Otolaryngol (2014) 35(6):741-6. doi: 10.1016/j.amjoto.2014.06.019

6. Omura K. Current Status of Oral Cancer Treatment Strategies: Surgical Treatments for Oral Squamous Cell Carcinoma. Int J Clin Oncol (2014) 19 (3):423-30. doi: 10.1007/s10147-014-0689-z

7. Grégoire V, Ang K, Budach W, Grau C, Hamoir M, Langendijk JA, et al. Delineation of the Neck Node Levels for Head and Neck Tumors: A 2013 Update. DAHANCA, EORTC, HKNPCSG, NCIC CTG, NCRI, RTOG, TROG Consensus Guidelines. Radiother Oncol (2014) 110(1):172-81. doi: 10.1016/j.radonc.2013.10.010

8. Zeng W, Qiu CY, Liu JF, Pan Y, Li R, Luo K, et al. The Preservation and Application of the Submandibular Gland in Oral Squamous Cell Carcinoma 
(STROBE). Med (Baltimore) (2019) 98(52):e18520. doi: 10.1097/MD. 0000000000018520

9. Gu B, Fang Q, Wu Y, Du W, Zhang X, Chen D. Impact of Submandibular Gland Preservation in Neck Management of Early-Stage Buccal Squamous Cell Carcinoma on Locoregional Control and Disease-Specific Survival. BMC Cancer (2020) 20(1):1034. doi: 10.1186/s12885-020-07534-5

10. Arain AA, Rajput MSA, Ansari SA, Mahmood Z, Ahmad AN, Dogar MR, et al. Occult Nodal Metastasis in Oral Cavity Cancers. Cureus (2020) 12(11): e11640. doi: 10.7759/cureus. 11640

11. d'Alessandro AF, Pinto FR, Lin CS, Kulcsar MA, Cernea CR, Brandão LG, et al. Oral Cavity Squamous Cell Carcinoma: Factors Related to Occult Lymph Node Metastasis. Braz J Otorhinolaryngol (2015) 81(3):248-54. doi: 10.1016/j.bjorl.2015.03.004

12. Bryne M, Koppang HS, Lilleng R, Kjaerheim A. Malignancy Grading of the Deep Invasive Margins of Oral Squamous Cell Carcinomas has High Prognostic Value. J Pathol (1992) 166(4):375-81. doi: 10.1002/path.1711660409

13. Lydiatt WM, Patel SG, O'Sullivan B, Brandwein MS, Ridge JA, Migliacci JC, et al. Head and Neck Cancers-Major Changes in the American Joint Committee on Cancer Eighth Edition Cancer Staging Manual. CA Cancer J Clin (2017) 67(2):122-37. doi: 10.3322/caac.21389

14. Crile GIII. On the Technique of Operations Upon the Head and Neck. Ann Surg (1906) 44(6):842-50. doi: 10.1097/00000658-190612000-00003

15. Bocca E, Pignataro O. A Conservation Technique in Radical Neck Dissection. Ann Otol Rhinol Laryngol (1967) 76(5):975-87. doi: 10.1177/000348946707600508

16. Cakir Cetin A, Dogan E, Ozay H, Kumus O, Erdag TK, Karabay N, et al. Submandibular Gland Invasion and Feasibility of Gland-Sparing Neck Dissection in Oral Cavity Carcinoma. J Laryngol Otol (2018) 132(5):446-51. doi: 10.1017/S0022215118000592

17. Byeon HK, Lim YC, Koo BS, Choi EC. Metastasis to the Submandibular Gland in Oral Cavity Squamous Cell Carcinomas: Pathologic Analysis. Acta Otolaryngol (2009) 129(1):96-100. doi: 10.1080/00016480802032801

18. Vessecchia G, Di Palma S, Giardini R. Submandibular Gland Metastasis of Breast Carcinoma: A Case Report and Review of the Literature. Virchows Arch (1995) 427(3):349-51. doi: 10.1007/BF00203404

19. Naidu TK, Naidoo SK, Ramdial PK. Oral Cavity Squamous Cell Carcinoma Metastasis to the Submandibular Gland. J Laryngol Otol (2012) 126(3):27984. doi: $10.1017 /$ S0022215111002660

20. Ebrahim AK, Loock JW, Afrogheh A, Hille J. Is it Oncologically Safe to Leave the Ipsilateral Submandibular Gland During Neck Dissection for Head and Neck Squamous Cell Carcinoma? J Laryngol Otol (2011) 125(8):837-40. doi: 10.1017/S0022215111001095

21. Yang S, Su JZ, Gao Y, Yu GY. Clinicopathological Study of Involvement of the Submandibular Gland in Oral Squamous Cell Carcinoma. Br J Oral Maxillofac Surg (2020) 58(2):203-7. doi: 10.1016/j.bjoms.2019.11.016

22. DiNardo LJ. Lymphatics of the Submandibular Space: An Anatomic, Clinical, and Pathologic Study With Applications to Floor-of-Mouth Carcinoma. Laryngoscope (1998) 108(2):206-14. doi: 10.1097/00005537-199802000-00009

23. Lin L, Lu Y, Wang XJ, Chen H, Yu S, Tian J, et al. Delineation of Neck Clinical Target Volume Specific to Nasopharyngeal Carcinoma Based on Lymph Node Distribution and the International Consensus Guidelines. Int J Radiat Oncol Biol Phys (2018) 100(4):891-902. doi: 10.1016/j.ijrobp.2017.11.004

24. Dhiwakar M, Ronen O, Malone J, Rao K, Bell S, Phillips R, et al. Feasibility of Submandibular Gland Preservation in Neck Dissection: A Prospective Anatomic-Pathologic Study. Head Neck (2011) 33(5):603-9. doi: 10.1002/ hed.21499
25. Jacob RF, Weber RS, King GE. Whole Salivary Flow Rates Following Submandibular Gland Resection. Head Neck (1996) 18(3):242-7. doi: 10.1002/(SICI)1097-0347(199605/06)18:3<242::AID-HED6>3.0.CO;2-\#

26. Razfar A, Walvekar RR, Melkane A, Johnson JT, Myers EN. Incidence and Patterns of Regional Metastasis in Early Oral Squamous Cell Cancers: Feasibility of Submandibular Gland Preservation. Head Neck (2009) 31 (12):1619-23. doi: 10.1002/hed.21129

27. Malgonde MS, Kumar M. Practicability of Submandibular Gland in Squamous Cell Carcinomas of Oral Cavity. Indian J Otolaryngol Head Neck Surg (2015) 67(Suppl 1):138-40. doi: 10.1007/s12070-014-0803-6

28. Chen TC, Lo WC, Ko JY, Lou PJ, Yang TL, Wang CP. Rare Involvement of Submandibular Gland by Oral Squamous Cell Carcinoma. Head Neck (2009) 31(7):877-81. doi: 10.1002/hed.21039

29. Lim YC, Koo BS, Lee JS, Lim JY, Choi EC. Distributions of Cervical Lymph Node Metastases in Oropharyngeal Carcinoma: Therapeutic Implications for the N0 Neck. Laryngoscope (2006) 116(7):1148-52. doi: 10.1097/ 01.mlg.0000217543.40027.1d

30. Dogan E, Cetinayak HO, Sarioglu S, Erdag TK, Ikiz AO. Patterns of Cervical Lymph Node Metastases in Oral Tongue Squamous Cell Carcinoma: Implications for Elective and Therapeutic Neck Dissection. J Laryngol Otol (2014) 128(3):268-73. doi: 10.1017/S0022215114000267

31. Markey JD, Morrel WG, Wang SJ, Ryan WR. The Effect of Submandibular Gland Preservation During Level 1B Neck Dissection on Postoperative Xerostomia. Auris Nasus Larynx (2018) 45(1):123-7. doi: 10.1016/j.anl. 2017.03.005

32. Jha N, Seikaly H, McGaw T, Coulter L. Submandibular Salivary Gland Transfer Prevents Radiation-Induced Xerostomia. Int J Radiat Oncol Biol Phys (2000) 46(1):7-11. doi: 10.1016/s0360-3016(99)00460-5

33. Jackson WC, Hawkins PG, Arnould GS, Yao J, Mayo C, Mierzwa M. Submandibular Gland Sparing When Irradiating Neck Level IB in the Treatment of Oral Squamous Cell Carcinoma. Med Dosim (2019) 44 (2):144-9. doi: 10.1016/j.meddos.2018.04.003

34. Subramaniam N, Balasubramanian D, Reddy R, Rathod P, Murthy S, Vidhyadharan S, et al. Determinants of Level Ib Involvement in Oral Squamous Cell Carcinoma and Implications for Submandibular GlandSparing Neck Dissection. Int J Oral Maxillofac Surg (2018) 47(12):1507-10. doi: 10.1016/j.ijom.2017.11.019

Conflict of Interest: The authors declare that the research was conducted in the absence of any commercial or financial relationships that could be construed as a potential conflict of interest.

Publisher's Note: All claims expressed in this article are solely those of the authors and do not necessarily represent those of their affiliated organizations, or those of the publisher, the editors and the reviewers. Any product that may be evaluated in this article, or claim that may be made by its manufacturer, is not guaranteed or endorsed by the publisher.

Copyright $\odot 2021$ Zhou, Chen, Zhou, Lian, Yan and Wu. This is an open-access article distributed under the terms of the Creative Commons Attribution License (CC BY). The use, distribution or reproduction in other forums is permitted, provided the original author(s) and the copyright owner(s) are credited and that the original publication in this journal is cited, in accordance with accepted academic practice. No use, distribution or reproduction is permitted which does not comply with these terms. 